\title{
Copy if dissatisfied, innovate if not: contrasting egg-laying decision making in an insect
}

\author{
$\operatorname{AUTHOR}(\mathrm{S})$ :
}

Otake, Ryoga; Dobata, Shigeto

\section{CITATION:}

Otake, Ryoga ... [et al]. Copy if dissatisfied, innovate if not: contrasting egg-laying decision making in an insect. Animal Cognition 2018, 21(6): 805-812

\section{ISSUE DATE:}

2018-11

URL:

http://hdl.handle.net/2433/234584

\section{RIGHT:}

This is a post-peer-review, pre-copyedit version of an article published in Animal Cognition. The final authenticated version is available online at: http://dx.doi.org/10.1007/s10071-018-1212-0; The full-text file will be made open to the public on 30 August 2019 in accordance with publisher's 'Terms and Conditions for Self-Archiving'.; This is not the published version. Please cite only the published version.; この論文は出版社版でありません。引用の際には出版社版 をご確認ご利用ください。 
1 Title: Copy if dissatisfied, innovate if not: contrasting egg-laying decision making

2 in an insect.

3

4 Authors: Ryoga Otake, Shigeto Dobata

5 Author affiliation: Laboratory of Insect Ecology, Graduate School of Agriculture, 6 Kyoto University.

7

8 Corresponding author: Shigeto Dobata

9 Laboratory of Insect Ecology, Graduate School of Agriculture, Kyoto University,

10 Kitashirakawa Oiwake-cho, Sakyo-ku, Kyoto 606-8502, Japan

11 Email: dobata@kais.kyoto-u.ac.jp

12 ORCID ID: 0000-0003-1586-6758

14 Abstract:

15 The use of conspecific cues as social information in decision-making is widespread among animals, but because this social information is indirect it is error-prone. During resource acquisition, conspecific cues also indicate the presence of competitors; therefore, decision-makers are expected to utilize direct information from resources and modify their responses to social information accordingly. Here, we show that, in a non-social insect, unattractive egg-laying resources alter the behavioural response to conspecific cues from avoidance to preference, leading to resource sharing. Females of the adzuki bean beetle Callosobruchus chinensis avoid laying eggs onto beans that already have conspecific eggs. However, when we provided females with bean-sized clean glass beads with and without conspecific eggs, the females preferred to add their eggs onto the beads with eggs. The glass beads, once coated with water extracts of adzuki beans, enabled the females to behave as if they were provided with the beans: the females preferred bean-odoured glass beads to clean glass beads and they avoided the substrates with eggs. When females are provided with unattractive egg-laying substrates only, joining behavior (i.e. copying) might be advantageous, as it takes advantage of information about positive attributes of the substrate that the focal animal might have missed. Our results suggest that given only unsatisfactory options, the

32 benefits of copying outweigh the costs of resource competition. Our study highlights the importance of integrating multiple information sources in animal decision-making. 
Keywords:

Insect cognition, Oviposition, Scent-marking, Seed beetle, Information cascade

\section{Introduction}

39 For organisms to survive and reproduce, the acquisition of information about the 40 environment, thereby reducing uncertainty, is crucial (Schmidt et al. 2011). Information 41 can be acquired by individuals not only through their own trial and error but also from 42 conspecific individuals (or their traces); such individuals may have already made 43 decisions in the same situation (Danchin et al. 2004). It is advantageous for an 44 individual to rely on such 'social information' when trial and error is costly (Dall et al. 45 2005, Grüter and Leadbeater 2014) or when some benefit is gained from joining with, or avoiding, conspecifics (Prokopy and Roitberg 2001). Animals, ranging from humans

47 to invertebrates (reviewed in Danchin et al. 2004; Grüter and Leadbeater 2014), have been shown to utilize, and benefit from, conspecific cues during decision-making in the contexts of predator avoidance (reviewed in Chivers and Smith 1998), foraging (birds, Ward and Zahavi 1973), habitat choice (birds, Betts et al. 2008; lizards, Stamps 1987), egg-laying substrate choice (insects, Fletcher and Miller 2008; Raitanen et al. 2013; Golden and Dukas 2014), and mate choice (reviewed in Nordell and Valone 1998; Westneat et al. 2000).

Despite the potential advantages accruing from the use of social information, for animal decision-makers that forage for resources, exclusive reliance on conspecific cues might be risky. Conspecific cues might reflect poor decisions (Giraldeau et al. 2002; Rieucau and Giraldeau 2011), and, even when they do not, the act of joining with conspecifics inevitably results in increased resource competition. Therefore, the information content of conspecific cues should be evaluated carefully and its importance relative to content derived from other information sources should be assessed. Even given identical social

62 information, animals may use the information differently depending on the private 63 information that is inherent in or acquired by themselves (Czaczkes et al. 2011; Wray et 64 al. 2011). Previous studies found that animals copy others when private information is costly (bees, Saleh et al. 2006; fish, Webster and Laland 2008; reviewed in Rieucau and 66 Giraldeau 2011), undesirable (rats, Galef et al. 2008; bees, Wray et al. 2011; bees, 
67 Grüter et al. 2013), unreliable (fish, Laland 2004; Rendell et al. 2010), outdated (fish,

68 Laland 2004; Rendell et al. 2010), or uncertain (fish, Laland 2004; Rendell et al. 2010;

69 rats, Galef et al. 2008; ants, Czaczkes and Beckwith 2018). These findings suggest that

70 animals acquire information from multiple sources and integrate them so that they can

71 make adaptive decisions (Grüter and Leadbeater 2014; Laland 2004).

72

73 In this study, we examined how the attractiveness to potential resources as private 74 information affects how animals use conspecific cues as social information in their 75 decision-making. During resource acquisition, the most reliable source of information is 76 the resources themselves. We investigated egg-laying decisions made by females of the 77 adzuki bean beetle, Callosobruchus chinensis. In laboratory-cultured conditions, the 78 female beetles lay eggs on the surfaces of beans (Fig. 1) and the hatched larvae burrow 79 into the beans to feed (Utida 1941). Because the larvae do not move to other beans, the 80 amount of larval food is predetermined by the decision-making of their mothers. The 81 females avoid laying eggs on beans when there are already conspecific eggs covered 82 with scent-marking chemicals (Oshima et al. 1973; Utida 1941; Yamamoto 1990). In 83 addition, their egg-laying decision is based on the odour (D-Catechin, Ueno et al. 1990) 84 and curvature (Avidov et al. 1965; Ishii 1951) of the potential substrate. We prepared 85 three different egg-laying substrates—namely, adzuki beans (Vigna angularis), clean 86 glass beads that had a similar curvature to the beans but lacked odour (Avidov et al. 87 1965; Ishii 1951), and glass beads coated with water extracts of adzuki beans, hereafter 88 referred to as odoured glass beads (Credland and Wright 1988; Gokhale et al. 1990; 89 Ueno et al. 1990). First, we confirmed that clean glass beads were less attractive than 90 adzuki beans and odoured beads for the females to lay eggs. Next, we provided the 91 females with only one of the above three substrate types and allowed them to choose 92 between the substrates with and without eggs. We then examined how the attractiveness 93 of resources affected how the females responded to the conspecific cue (the presence of 94 conspecific eggs) in egg-laying decisions.

96 Materials and methods

97 Insects.

98 Callosobruchus chinensis is a pest beetle attacking stored legumes such as the adzuki 99 bean Vigna angularis and the cowpea V. unguiculata (Fujii et al. 1990). Adult females 
100 lay eggs on the surface of host beans or bean pods, and hatched larvae burrow into the

101 bean in which they complete their development into adults. Adult $C$. chinensis can

102 reproduce without any food supply, which makes this species an ideal model organism

103 in laboratory studies of population and behavioral ecology (Yoshida 1990). We

104 established a new laboratory strain (fkC16) of C. chinensis from at least 10 individuals

105 (including adults and eggs) collected at the farm field of Kyoto University

106 (N35.031294 $\left.{ }^{\circ}, \mathrm{E} 135.787047^{\circ}\right)$ in October 2016. The strain was maintained on adzuki

107 beans (Vigna angularis “Toyomi-dainagon” cropped in Hokkaido, Japan; Hasebe Shoji)

108 in plastic Petri dishes (Ø90 mm, height $15 \mathrm{~mm}$ ) at $30{ }^{\circ} \mathrm{C}$ and $70 \%$ relative humidity

109 under a 16:8-hour light:dark cycle. Beans were added every 1 to 3 weeks to make

110 beetles' generations continuous. We collected virgin beetles from the stock culture by

111 putting beans (at one bean per well) in 24-well cell culture plates (IWAKI, Japan) just

112 before adult emergence and then checking each well daily for adult females that had

113 either emerged singly or were all the same sex. All beetles were kept individually in a

114 plastic tube $\left(1.5 \mathrm{~mL}\right.$, VIOLAMO) without beans in a room maintained at $20^{\circ} \mathrm{C}$ until the

115 experiments. Three to six hours prior to experiments, each virgin female was placed

116 with a virgin male in a plastic tube at $25^{\circ} \mathrm{C}$ for 1 hour to induce mating.

118 Experiments. The experiments were conducted at $25^{\circ} \mathrm{C}$ in lighted conditions. We used 119 adzuki beans (long axis: mean \pm SEM $=8.85 \pm 0.0654 \mathrm{~mm}$; short axis: $7.05 \pm 0.0444$ $120 \mathrm{~mm} ; n=30$ ), transparent glass beads (diameter: $8.95 \pm 0.0145 \mathrm{~mm} ; n=30$, washed with 121 ethanol and distilled water, ING-GLASS, Japan) as egg-laying substrates. In order to 122 make odoured glass beads, we placed 200 adzuki beans in a clean glass beaker and 123 added $300 \mathrm{ml}$ distilled water. After $24 \mathrm{~h}$ soaking with occasional agitation, the water 124 solution was poured to another beaker. We added 200 glass beads to the liquid and after 12530 minutes soaking, the glass beads were removed and then were dried under reduced 126 pressure. In the first experiment, we placed each pair of substrates (i.e. one bean and 127 one clean bead, one bean and one odoured bead, or one clean bead and one odoured 128 bead) into a plastic Petri dish (Ø35 mm, height $10 \mathrm{~mm}$ ) (Fig. 2a). Then, the females 129 were placed individually into the Petri dishes and allowed to lay eggs for 1 hour, after 130 which we counted the eggs laid on both substrates. Subsequently, each female was 131 transferred to a plastic tube with an adzuki bean to confirm her egg-laying ability; if she 132 died without laying eggs in the tube, then her data were omitted from subsequent 
133 analyses. In the second experiment, to prepare the substrates with conspecific eggs, we

134 allowed 10 mated females (separately prepared) to lay eggs on 10 substrates of each 135 type in a plastic Petri dish (Ø35 mm, height $10 \mathrm{~mm}$ ) for 1 to 6 hours until we had 136 enough substrates with eggs for the experiments. Clean substrates without eggs were 137 used as negative controls. We placed four substrates (beans, clean beads or odoured 138 beads) into a plastic Petri dish, one of which, called the focal substrate, had zero or 139 more conspecific eggs, and was at a fixed position in the experimental arena (Fig. 2b).

140 Then we allowed a female to lay eggs for 1 hour as described above and counted the 141 eggs laid on each of the four substrates.

143 Statistical Analyses. We fitted generalized linear mixed models (GLMMs) to the egg 144 distribution data of the experimental females. The GLMMs assumed a Poisson error 145 distribution of the response variable with the log-link function (for the first experiment) 146 or a binomial error distribution with the logit-link function (for the second experiment), and the following model was used:

149 First experiment:

Second experiment:

In the second experiment, the effect of conspecific cue intensity (\#Initial eggs) was evaluated sequentially up to its squared term. Individual differences (female ID) were included as a random effect (random intercept), and the maximum-likelihood estimation with Laplace approximation was used for the fitting. We used likelihood-ratio tests to evaluate the effect of adding the explanatory variables in the models. The tests were conducted separately for each type of substrate. All statistical analyses were conducted with R version 3.4.1 software (R Core Team 2017).

\section{Results}

163 In the first experiment, females obviously laid more eggs onto adzuki beans compared 164 to clean glass beads and odoured glass beads (vs. clean beads: slope $\pm \mathrm{SEM}=3.3322 \pm$ 165 0.7196, $\chi_{1}^{2}=63.006, p<0.0001, n=30$, Fig. 3a; vs. odoured beads: slope $\pm \mathrm{SEM}=$ 
166

167

168

169

170

171

172

173

174

175

176

177

178

179

180

181

182

183

184

185

186

187

188

189

190

191

192

193

194

195

196

197

198

$2.5177 \pm 0.3287, \chi_{1}^{2}=114.62, p<0.0001, n=25$, Fig. 3b), and females laid more eggs onto odoured glass beads than clean glass beads (slope $\pm \mathrm{SEM}=1.1109 \pm 0.2219, \chi_{1}^{2}=$ 29.069, $p<0.0001, n=26$, Fig. 3c).

In the second experiment, females showed stronger avoidance of the focal adzuki beans when they had more conspecific eggs (slope $\pm \mathrm{SEM}=-0.4571 \pm 0.1221, \chi_{1}^{2}=25.429$, $p<0.0001, n=72$ ) (Fig. 4a). The effect of adding the squared term of conspecific cue intensity was not statistically significant $\left(\chi_{1}^{2}=0.0261, p=0.8715\right)$. The avoidance-inducing effect of the number of conspecific eggs was also observed in odoured glass beads with conspecific eggs (slope \pm SEM $=-0.1124 \pm 0.0549, \chi_{1}^{2}=$ 4.531, $p=0.0333, n=66$ ) (Fig. 4b), with a non-significant effect of its squared term $\left(\chi_{1}^{2}=0.5091, p=0.4755\right)$. The avoidance-inducing effect was weaker in the odoured beads treatment than in the adzuki bean treatment, which was indicated by a statistically significant interaction between the number of conspecific eggs and the type of substrates (in the statistical analysis, data of adzuki bean and odoured glass bead treatments were combined and were coded by 0 and 1 , respectively, and only the linear effects were considered; coefficient $\pm \mathrm{SEM}=0.2960 \pm 0.1127, \chi_{1}^{2}=7.855, p=0.0051$ ) (Fig. 4ab). In stark contrast, they showed an overall preference for focal clean glass beads with conspecific eggs (Fig. 4c). The strongest preference was for focal clean beads with a moderate number of conspecific eggs, as indicated by the statistically significant negative quadratic term of the regression (coefficient \pm SEM $=-0.1914 \pm$ 0.07166, $\chi_{1}^{2}=4.546, p=0.033, n=99$ ). An additional analysis that excluded the intensity of conspecific cues showed that the observed proportions of eggs on the focal substrate were overall significantly lower than the theoretical value of chance $(=0.25)$ when laid on adzuki beans (mean proportion $=0.149, G$-test, $G=181.79$, d.f. $=71, p<$ 0.0001 ) and on odoured glass beads (mean proportion $=0.178, G=133.26$, d.f. $=65, p$ $<0.0001$ ), whereas they were overall significantly higher than 0.25 when laid on clean glass beads (mean proportion $=0.633 ; G=433.21$, d.f. $=98, p<0.0001$ ).

\section{Discussion}

In the first experiment, females obviously preferred adzuki beans to glass beads as egg-laying substrates (Fig. 3a), even when the glass beads were coated with bean extracts (Fig. 3b). These results strongly suggest that females indeed evaluate the 
199 egg-laying substrate itself, and that the glass beads were less attractive substrates for

200 beetles than adzuki beans. Moreover, they preferred odoured glass beads to clean glass

201 beads (Fig. 3c), which suggests that the attractiveness was in part attributed to the

202 water-soluble fraction of adzuki beans (see also Gokhale et al. 1990; Ueno et al. 1990).

203 In the second experiment, females avoided laying eggs on beans with conspecific eggs

204 (Fig. 4a), which confirms previous studies (e.g., Utida 1941; Yoshida et al. 1990). In

205 stark contrast, however, when females are provided with clean glass beads with and

206 without conspecific eggs, they preferred to add their eggs onto the beads with eggs (Fig.

207 4c).

208

209 As an important methodological control, the odoured glass beads successfully induced

210 the females to show avoidance of the conspecific cue that was similar to what was

211 observed in adzuki beans (Fig. 4b). The glass bead has long been used as an artificial

212 egg-laying substrate in bean beetle research (e.g., Avidov et al. 1965; Credland and

213 Wright 1988; Gokhale et al. 1990; Ishii 1951; Ueno et al. 1990). Our result could rule

214 out the possibility that the artificial substrate itself automatically triggered a preference

215 for moderate numbers of conspecific eggs or our artificial setup induced any kinds of

216 irregular behaviors. Interestingly, the avoidance of conspecific eggs on odoured glass

217 beads was weaker than those on adzuki beans (Fig. 4ab). This would commensurate

218 with the odoured beads being less attractive than adzuki beans, reflecting an

219 intermediate state between beans and clean beads.

220

221 The contrast between avoidance and preference of the same social information on

222 different resources might be generalized as a decision-making strategy consisting of two

223 alternative tactics "copy if dissatisfied, innovate if not." The former is already reported

224 from rats (Galef et al. 2008) and honeybees (Grüter et al. 2013; Wray et al. 2011),

225 where the decision of copying others is made when the payoff from private information

226 is below an internal threshold reward level (reviewed in Grüter and Leadbeater 2014).

227 Nevertheless, when combined with the latter “innovate if not,” i.e., keeping away from

228 social information and finding their own ways for novel resources when the given

229 resource is satisfactory, these contrasting decisions have an important implication for

230 the adaptive significance of socially-mediated decision making as discussed below. 
232 Because the larvae of this species do not move to other beans, when females lay 233 multiple eggs onto the same bean, competition among the hatched conspecific larvae 234 should be intense for this limited food resource. Beans already populated with 235 conspecific eggs indicate the presence of competitors. Therefore, the tactic "innovate if not,” i.e., avoiding others during egg laying onto satisfactory resources, should be an evolutionary adaptation to avoid disadvantageous resource competition for the females'

238 offspring. Note that avoiding others can also be interpreted as a part of social 239 information use (Prokopy and Roitberg 2001). Given the cost of resource competition, 240 there might be some benefits of taking the tactic "copy if dissatisfied" that outweigh the 241 cost. Copying others, or laying eggs on substrates already with conspecific eggs, might

242 benefit female $C$. chinensis in two ways. First, it might enable females to locate correct 243 substrates more quickly than would be possible by trial and error (Dall et al. 2005); 244 given the limited lifespan of the beetle, this might be an important benefit. Second, under information asymmetry between individuals, females that have poorer private information of resources might be more likely to lay eggs on appropriate resources when copying decisions of others, compared to relying on their own. Information asymmetry could be caused by accidental events such as olfactory dysfunction or by the degradation of information from resources (e.g., bean odour) over time. Resource-choice copying would then be beneficial despite the resource competition among facing their offspring.

253 Although our study used artificial clean glass beads as an unattractive egg-laying substrate, the clear behavioral change of females would suggest the existence of corresponding situations when they lay eggs in the field. In natural habitats of $C$. chinensis, laying eggs on bean pods might be one of the undesirable situations. In adzuki bean fields, the larval food is hidden in bean pods whose curvature and odour are different from, and possibly more changeable than, those of beans. Therefore, it might be more advantageous to prefer conspecific cues when laying eggs on bean pods as well as on the glass beads. A previous study reported that the distribution of eggs was clumped among bean pods in the field, while they showed uniform distribution among

262 beans themselves (Shinoda 1989). More study is required to examine whether the

263 clustering of eggs on bean pods is caused by beetles copying the behaviours of other 264 females. More generally, patterns of social information use during egg laying might 
265 vary among closely related species of the genus Callosobruchus (e.g., Messina and

266 Karren 2003; Messina and Jones 2009; Parr et al. 1998) and even within C. chinensis

267 depending on strains. The ecological covariates of varying social information use would

268 be an interesting topic for future research.

269

270 The acquired private information such as familiarity with, or knowledge of, a resource

271 is known to change the behavioural response of an animal to conspecific cues (Grüter

272 and Leadbeater 2014; Kawaguchi et al. 2007). However, we observed contrasting

273 responses in our experiments even though the females had no prior experience of the

274 resources. This suggests that the avoidance and joining behaviours in $C$. chinensis

275 would probably be an inherent (i.e., genetically encoded) behavioral response.

276 Moreover, the observed behavioural change seemed drastic, even when compared with

277 other reported resource-mediated behavioural changes that have occurred without

278 learning (Heard 1994; Papaj and Messing 1996; Prokopy and Roitberg 2001), including

279 behavioural changes in other bean beetles (Cope and Fox 2003), because these previous

280 studies observed a change from a neutral response (neither preference nor avoidance) to

281 one of avoidance or preference. The drastic change observed in our experiments

282 suggests that the switch from avoidance to joining behaviour in $C$. chinensis may

283 involve inherent mechanisms that have been shaped by complex evolutionary

284 adaptation in response to resource attractiveness. Interestingly, we detected a

285 statistically significant decrease in the number of eggs added to glass beads when an

286 excessive number of conspecific eggs were presented together (Fig. 4c). This result also

287 suggests that females are able to compare the costs and benefits of joining behavior (see

288 also Fig. S1 in Electronic supplementary material). A previous study reported that $C$.

289 subinnotatus, a closely related species of $C$. chinensis, does not rely on vision when

290 assessing egg-laying substrate (Mbata 1994). Together with potential visual and

291 numerical cognition of eggs on substrates, the cognitive ability of $C$. chinensis deserves

292 further study.

293

294 The chemical basis of attractive conspecific cues, as well as the information acquired

295 from the resources themselves, is left for future study. Because $C$. chinensis is a pest

296 species, chemical egg-laying deterrents left by conspecific females have already been

297 identified (Oshima et al. 1973; Yamamoto 1990) and constitute a mixture of fatty acids, 
298 hydrocarbons and triglycerides secreted from their bodies. Of particular interest is

299 whether these same chemicals would function as an attractant for egg-laying if they

300 were put onto unattractive substrates. Our findings of copying behaviour on glass beads

301 might open perspectives for a biologically safe way (i.e., clean glass beads or perhaps

302 strongly odoured glass beads as decoys to attract egg laying females) to control bean

303 beetles. In conclusion, our study provides a novel opportunity for further investigations

304 of the underlying physiological, behavioural, cognitive and neural mechanisms

305 underlying flexible decision-making by animals and their ability to integrate 306 information from multiple sources.

307

308

309 Acknowledgements: We thank Ken Cheng and three anonymous referees for 310 constructive comments on earlier drafts. We also thank K. Matsuura, members of 311 Laboratory of Insect Ecology, and Y. Toquenaga for their discussions and laboratory 312 support.

313

314 Funding: This study was partly supported by the Japan Society for the Promotion of 315 Science (15K18609 to S.D.).

316

317 Ethical approval: All applicable international, national, and/or institutional 318 (Regulation on Animal Experimentation of Kyoto University) guidelines for the care 319 and use of animals were followed.

320

321 Conflict of Interest: The authors declare that they have no conflict of interest.

\section{References}

324 Avidov Z, Berlinger MJ, Applebaum SW (1965) Physiological aspects of host 325 specificity in the Bruchidae: III. Effect of curvature and surface area on oviposition 326 of Callosobruchus chinensis L. Anim Behav 13:178-180. 327 https://doi.org/10.1016/0003-3472(65)90089-8 
328

329

330

331

332

333

334

335

336

337

338

339

340

341

342

343

344

345

346

347

348

349

350

351

352

353

354

355

356

357

358

359

360

Betts MG, Hadley AS, Rodenhouse N, Nocera JJ (2008) Social information trumps vegetation structure in breeding-site selection by a migrant songbird. Proc R Soc B 275:2257-2263. https://doi.org/10.1098/rspb.2008.0217

Chivers DP, Smith RJF (1998) Chemical alarm signalling in aquatic predator-prey systems: A review and prospectus. Écoscience 5:338-352. https://doi.org/ 10.1080/11956860.1998.11682471

Cope JM, Fox CW (2003) Oviposition decisions in the seed beetle, Callosobruchus maculatus (Coleoptera: Bruchidae): effects of seed size on superparasitism. J Stored Prod Res 39:355-365. https://doi.org/10.1016/S0022-474X(02)00028-0

Credland PF, Wright AW (1988) The effect of artificial substrates and host extracts on oviposition by Callosobruchus maculatus (F.) (Coleoptera: Bruchidae). J Stored Prod Res 1-8. https://doi.org/10.1016/0022-474X(88)90013-6

Czaczkes TJ, Beckwith JJ (2018) Information synergy: adding unambiguous quality information rescues social information use in ants. bioRxiv 1-18. https://doi.org/10.1101/219980

Czaczkes TJ, Gruter C, Jones SM, Ratnieks FLW (2011) Synergy between social and private information increases foraging efficiency in ants. Biol Lett 7:521-524. https://doi.org/10.1098/rsbl.2011.0067

Dall S, Giraldeau L, Olsson O, Mcnamara J, Stephens D (2005) Information and its use by animals in evolutionary ecology. Trends Ecol Evol 20:187-193. https://doi.org/10.1016/j.tree.2005.01.010

Danchin E, Giraldeau LA, Valone TJ, Wagner RH (2004) Public information: from noisy neighbors to cultural evolution. Science 305:487-491. https://doi.org/10.1126/science.1098254

Fletcher RJ, Miller CW (2008) The type and timing of social information alters offspring production. Biol Lett 4:482-485. https://doi.org/10.1098/rsbl.2008.0306

Fujii K, Gatehouse AMR, Johnson CD, Mitchel R, Yoshida T (eds.) (1990) Bruchids and Legumes: Economics, Ecology and Coevolution. Dordrecht: Springer Netherlands. Kluwer Academic Publishers. https://doi.org/10.1007/978-94-009-2005-7_1

Galef BG, Dudley KE, Whiskin EE (2008) Social learning of food preferences in 'dissatisfied' and 'uncertain' Norway rats. Anim Behav 75:631-637. https://doi.org/10.1016/j.anbehav.2007.06.024 
361 Giraldeau LA, Valone TJ, Templeton JJ (2002) Potential disadvantages of using

362

363

364

365

366

367

368

369

370

371

372

373

374

375

376

377

378

379

380

381

382

383

384

385

386

387

388

389

390

391

392

socially acquired information. Philos Trans R Soc B 357:1559-1566. https://doi.org/10.1098/rstb.2002.1065

Grüter C, Leadbeater E (2014) Insights from insects about adaptive social information use. Trends Ecol Evol 29:177-184. https://doi.org/10.1016/j.tree.2014.01.004

Grüter C, Segers FHID, Ratnieks FLW (2013) Social learning strategies in honeybee foragers: do the costs of using private information affect the use of social information? Anim Behav 85:1443-1449. https://doi.org/10.1016/j.anbehav.2013.03.041

Gokhale VG, Honda H, Yamamoto I. (1990) Role of Physical and Chemical Stimuli of Legume Host Seeds in Comparative Ovipositional Behaviour of Callosobruchus maculatus (Fab.) and C. chinensis (Linn.) (Coleoptera: Bruchidae). In Fujii K, Gatehouse AMR, Johnson CD, Mitchel R, Yoshida T (eds.) Bruchids and Legumes: Economics, Ecology and Coevolution. Dordrecht: Springer Netherlands. Kluwer Academic Publishers. https://doi.org/10.1007/978-94-009-2005-7_4

Golden S, Dukas R (2014) The value of patch-choice copying in fruit flies. PLoS ONE 9:e112381. https://doi.org/10.1371/journal.pone.0112381

Heard SB (1994) Imperfect oviposition decisions by the pitcher plant mosquito Wyeomyia smithii. Evol Ecol 8:493-502. https://doi.org/10.1007/BF01238254

Ishii S (1951) Studies on the host preference of the cowpea weevil (Callosobruchus chinensis L.). Bull Nat Inst Agric Science Ser C1:185-256.

Kawaguchi LG, Ohashi K, Toquenaga Y (2007) Contrasting responses of bumble bees to feeding conspecifics on their familiar and unfamiliar flowers. Proc $\mathrm{R}$ Soc $\mathrm{B}$ 274:2661-2667. https://doi.org/10.1098/rspb.2007.0860

Laland KN (2004) Social learning strategies. Anim Learn Behav 32:4-14. https://doi.org/10.3758/BF03196002

Messina FJ, Karren ME (2003) Adaptation to a novel host modifies host discrimination by the seed beetle Callosobruchus maculatus. Anim Behav 65:501-507. https://doi.org/10.1006/anbe.2003.2107

Messina FJ, Jones JC (2009) Does rapid adaptation to a poor-quality host by Callosobruchus maculatus (F.) cause cross-adaptation to other legume hosts? J Stored Prod Res 45:215-219. https://doi.org/10.1016/j.jspr.2009.02.004 
393

394

395

396

397

398

399

400

401

402

403

404

405

406

407

408

409

410

411

412

413

414

415

416

417

418

419

420

421

422

423

424

425

Mbata GN (1994) Sensory organs involved in egg distribution in Callosobruchus subinnotatus Pic. (Coleoptera: Bruchidae). J Stored Prod Res 30:339-346. https://doi.org/10.1016/S0022-474X(94)90325-5

Nordell SE, Valone TJ (1998) Mate choice copying as public information. Ecol Lett 1:74-76. https://10.1046/j.1461-0248.1998.00025.x

Oshima K, Honda H, Yamamoto I (1973) Isolation of an oviposition marker from Azuki bean weevil, Callosobruchus chinensis (L.). Agric Biol Chem 37:2679-2680. https://doi.org/10.1080/00021369.1973.10861061

Papaj DR, Messing RH (1996) Functional shifts in the use of parasitized hosts by a tephritid fly: the role of host quality. Behav Ecol 7:235-242. https://doi.org/10.1093/beheco/7.3.235

Parr MJ, Tran BMD, Simmonds MSJ, Kite C, Credland PF (1998) Influence of Some Fatty Acids on Oviposition by the Bruchid Beetle, Callosobruchus maculatus. J Chem Ecol 24:1577-1593. https://doi.org/10.1023/A:1020894410107

Prokopy RJ, Roitberg BD (2001) Joining and avoidance behavior in nonsocial insect. Annu Rev Entomol 46:631-665. https://doi.org/10.1146/annurev.ento.46.1.631

Raitanen J, Forsman JT, Kivelä SM, Mäenpää MI, Välimäki P (2013) Attraction to conspecific eggs may guide oviposition site selection in a solitary insect. Behav Ecol 25:110-116. https://doi.org/10.1093/beheco/art092

R Core Team (2017) R: A Language and Environment for Statistical Computing. Vienna, Austria: R Foundation for Statistical Computing. (See https://www.R-project.org/)

Rieucau G, Giraldeau LA (2011) Exploring the costs and benefits of social information use: an appraisal of current experimental evidence. Philos Trans R Soc B 366:949957. https://doi.org/10.1098/rstb.2010.0325

Saleh N, Ohashi K, Thomson JD, Chittka L (2006) Facultative use of the repellent scent mark in foraging bumblebees: complex versus simple flowers. Anim Behav 71:847854. https://doi.org/10.1016/j.anbehav.2005.06.014

Schmidt KA, Dall SRX, van Gils JA (2010) The ecology of information: an overview on the ecological significance of making informed decisions. Oikos 119:304-316. https://doi.org/10.1111/j.1600-0706.2009.17573.x

Shinoda K (1989) Studies on life cycle of azuki bean beetle in the field. Okayama University Ph. D. thesis. (in Japanese) 
426

427

428

429

430

431

432

433

434

435

436

437

438

439

440

441

442

443

444

445

446

447

448

449

450

451

452

453

454

455

456

457

Stamps JA (1987) Conspecifics as Cues to Territory Quality: A Preference of Juvenile Lizards (Anolis aeneus) for Previously Used Territories. Am Nat 129:629-642. https://doi.org/10.1086/284663

Ueno T, Kuwahara Y, Fujii K, Taper ML, Toquenaga Y, Suzuki T (1990) D-Catechin: An oviposition stimulant of azuki bean weevil Callosobruchus chinensis in the host azuki bean. J Pestic Sci 15:573-578. https://doi.org/10.1584/jpestics.15.573

Utida S (1941) Studies on experimental population of the azuki bean weevil, Callosobruchus chinensis L. Kyoto: Memoirs of the College of Agriculture, Kyoto Imperial University.

Valone TJ, Templeton JJ (2002) Public information for the assessment of quality: a widespread social phenomenon. Philos Trans R Soc B 357:1549-1557. https://doi.org/10.1098/rstb.2002.1064

Ward P, Zahavi A (1973) The Importance of certain assemblages of birds as “information-centres” for food-finding. Ibis, 115, 517-534.

Webster MM, Laland KN (2008) Social learning strategies and predation risk: minnows copy only when using private information would be costly. Proc Biol Sci 275:28692876. https://doi.org/10.1098/rspb.2008.0817

Westneat DF, Walters A, McCarthy TM, et al (2000) Alternative mechanisms of nonindependent mate choice. Anim Behav 59:467-476. https://doi.org/10.1006/anbe.1999.1341

Wray MK, Klein BA, Seeley TD (2011) Honey bees use social information in waggle dances more fully when foraging errors are more costly. Behav Ecol 23:125-131. https://doi.org/10.1093/beheco/arr165

Yamamoto I (1990) Chemical ecology of bruchids. In Fujii K, Gatehouse AMR, Johnson CD, Mitchel R, Yoshida T (eds.) Bruchids and Legumes: Economics, Ecology and Coevolution. Dordrecht: Springer Netherlands. Kluwer Academic Publishers. https://doi.org/10.1007/978-94-009-2005-7_1

Yoshida T (1990) Historical review of Bruchid studies in Japan In Fujii K, Gatehouse AMR, Johnson CD, Mitchel R, Yoshida T (eds.) Bruchids and Legumes: Economics, Ecology and Coevolution. Dordrecht: Springer Netherlands. Kluwer Academic Publishers. https://doi.org/10.1007/978-94-009-2005-7_1 


\section{$459 \quad$ Figure legends}

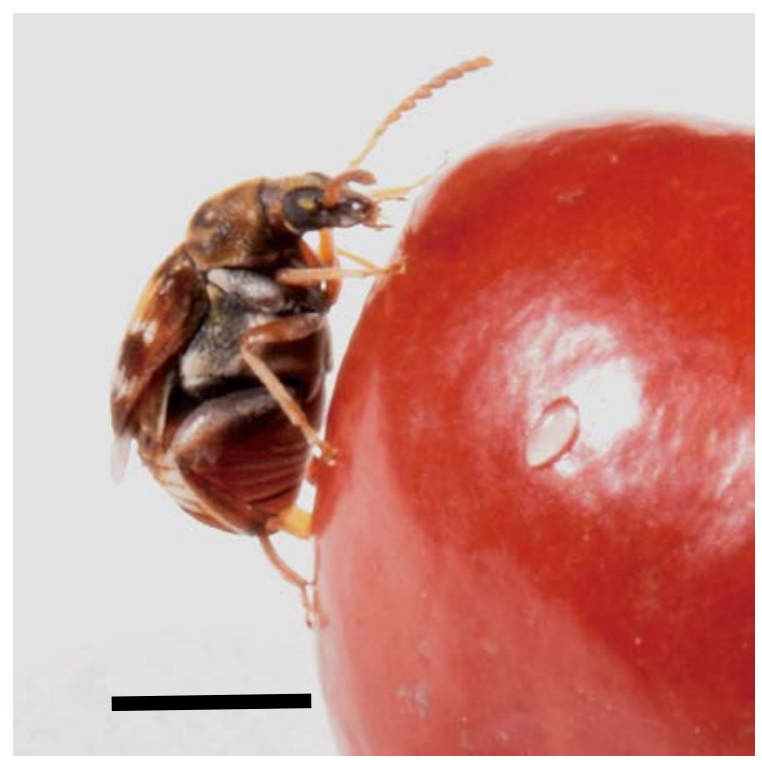

460

461 Figure 1. A female adzuki bean beetle Callosobruchus chinensis laying an egg on an 462 adzuki bean (scale bar, $2 \mathrm{~mm}$ ). 
467 Figure 2. Snapshots of the experimental 468 arena. (a) In the first experiment, 469 egg-laying substrates of different types 470 were paired and placed in a plastic Petri 471 dish. (b, c) In the second experiment, 472 four potential substrates (i.e., four beans, 473 four clean beads, or four odoured beads) 474 were placed in a Petri dish; among these 475 substrates, only one (the focal substrate) 476 had conspecific eggs (arrowheads; scale 477 bar, $10 \mathrm{~mm})$. 
a ${ }^{8-}$
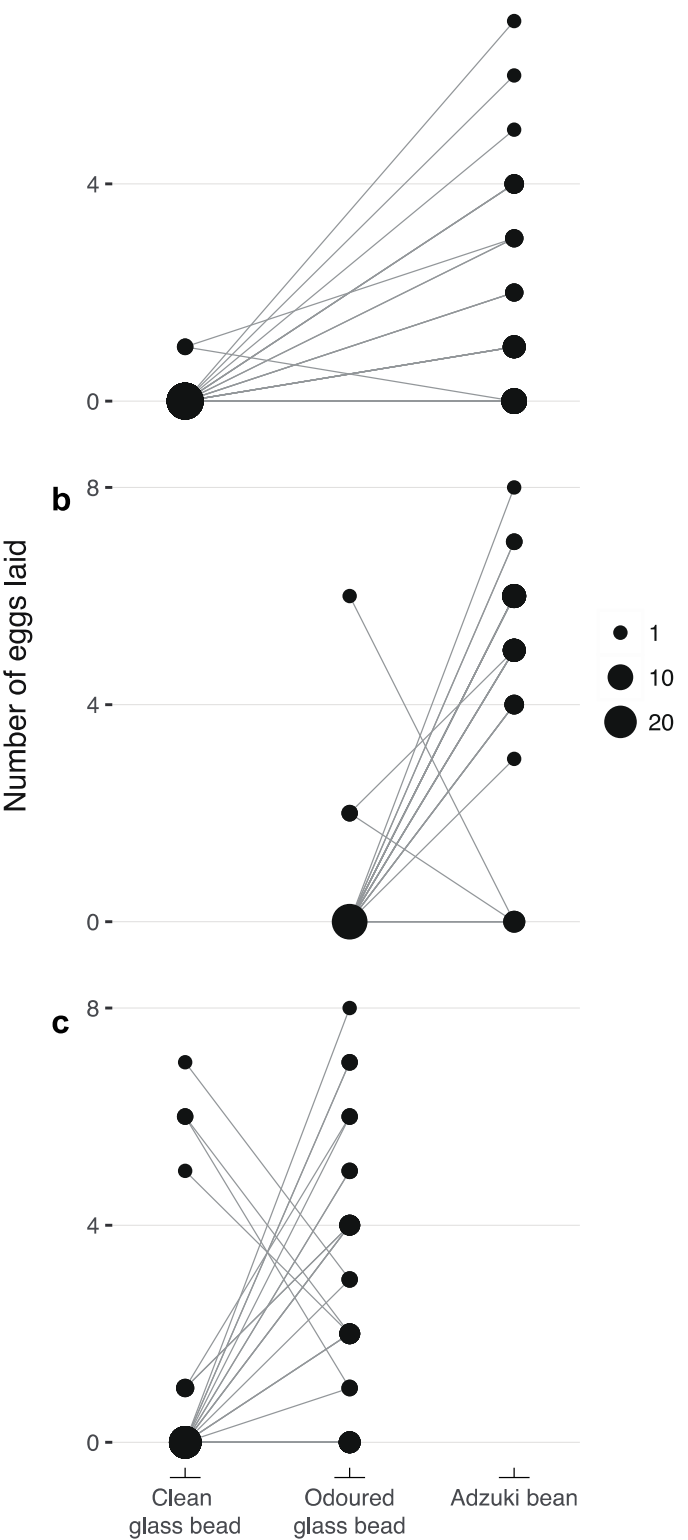

478

479

480

481

482

483

484

485

486

487
488 Figure 3. $(\mathrm{a}-\mathrm{c})$ Total numbers of eggs 489 laid by females within 1 hour on each 490 pair of egg-laying substrates in the first 491 experiment. Each line connecting two 492 data points represents one female and 493 overlapping of the data points was 494 indicated by the size of the circle. 


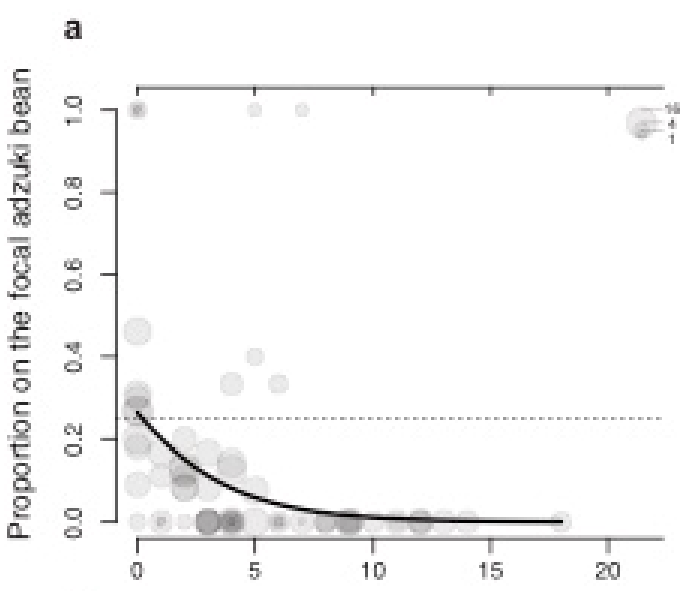

503 Figure 4. Proportions of eggs laid on 504 the focal (a) adzuki bean, (b) odoured 505 glass bead, and (c) clean glass bead in 506 the second experiment. Each datapoint 507 (depicted by a circle) corresponds to a 508 result obtained from one female. The 509 size of the circle reflects the total 510 number of eggs laid by that female in 1 511 hour, and overlapping of the data points

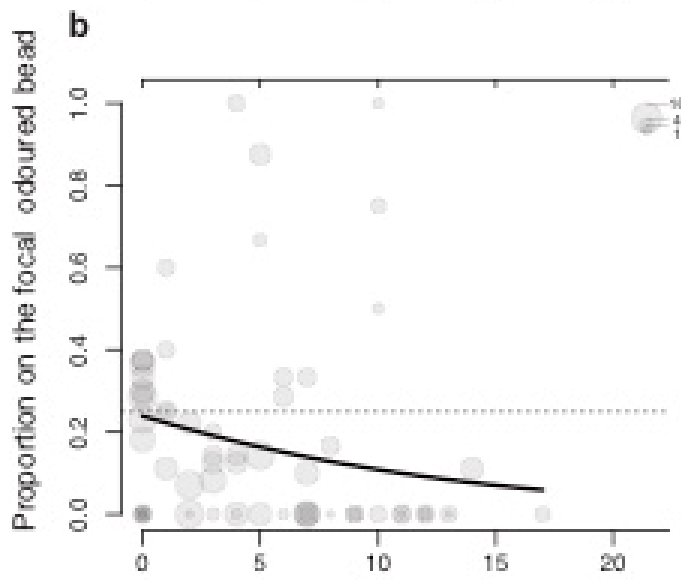
512 was indicated by shading. GLMM-fitted 513 curves are shown together. The dotted 514 line indicates the proportion expected 515 given a random substrate choice (= 516 0.25).

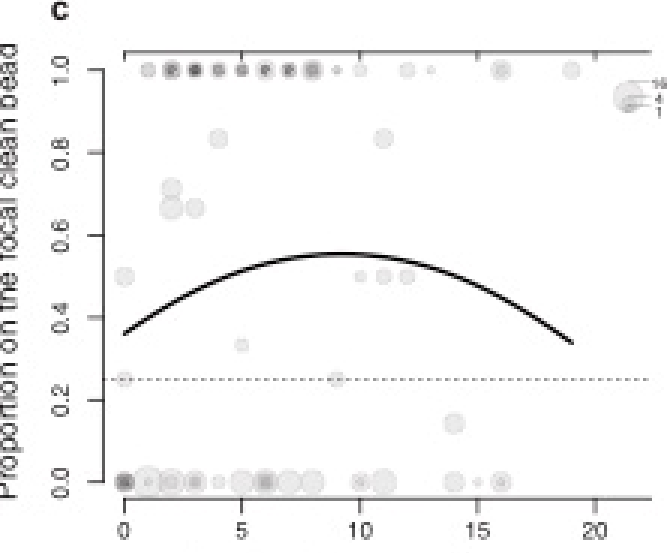

